OPEN ACCESS

Edited by:

Yen San Chan,

Curtin University Sarawak, Malaysia

Reviewed by:

Xiao-Feng $L i$,

Anhui Medical University, China

Ganesan Ramamoorthi,

Moffitt Cancer Center, United States

*Correspondence:

Yukuan Tang

tyk20126@126.com

Yu Luo

yuluo@sues.edu.cn

Quan Zhou

zhouquan3777@smu.edu.cn

Wenli Chen

chenwl@scnu.edu.cn

Specialty section: This article was submitted to

Nanobiotechnology,

a section of the journal

Frontiers in Bioengineering and

Biotechnology

Received: 24 November 2021

Accepted: 14 January 2022

Published: 28 February 2022

Citation:

Zhang $C$, Huang $W$, Huang $C$, Zhou $C$,

Tang Y, Wei W, Li Y, Tang Y, Luo Y,

Zhou $Q$ and Chen W (2022) VHPKQHR

Peptide Modified Ultrasmall

Paramagnetic Iron Oxide

Nanoparticles Targeting Rheumatoid Arthritis for $T_{1}$-Weighted Magnetic

Resonance Imaging.

Front. Bioeng. Biotechnol. 10:821256.

doi: 10.3389/fbioe.2022.821256

\section{VHPKQHR Peptide Modified Ultrasmall Paramagnetic Iron Oxide Nanoparticles Targeting Rheumatoid Arthritis for $\mathrm{T}_{1}$-Weighted Magnetic Resonance Imaging}

\author{
Chunyu Zhang 1,2,3, Wentao Huang ${ }^{1,2,3}$, Chen Huang ${ }^{4}$, Chengqian Zhou ${ }^{5}$, Yukuan Tang ${ }^{4}$,
} Wei Wei ${ }^{6}$, Yongsheng $\mathrm{Li}^{6}$, Yukuan Tang ${ }^{4 *}$, Yu Luo ${ }^{7 *}$, Quan Zhou ${ }^{8 *}$ and Wenli Chen ${ }^{1,2,3 *}$

${ }^{1}$ MOE Key Laboratory of Laser Life Science, Institute of Laser Life Science, College of Biophotonics, South China Normal University, Guangzhou, China, 'ªuangdong Provincial Key Laboratory of Laser Life Science, College of Biophotonics, South China Normal University, Guangzhou, China, ${ }^{3}$ Guangzhou Key Laboratory of Spectral Analysis and Functional Probes, College of Biophotonics, South China Normal University, Guangzhou, China, ${ }^{4}$ Department of Minimally Invasive Interventional Radiology, Guangzhou Panyu Central Hospital, Guangzhou, China, ${ }^{5}$ Neuroscience Laboratory, Hugo Moser Research Institute at Kennedy Krieger, Baltimore, MD, United States, ${ }^{6}$ Institution of GuangDong Cord Blood Bank, Guangzhou, China, ${ }^{7}$ Shanghai Engineering Technology Research Center for Pharmaceutical Intelligent Equipment, Shanghai Frontiers Science Research Center for Druggability of Cardiovascular Noncoding RNA, Institute for Frontier Medical Technology, College of Chemistry and Chemical Engineering, Shanghai University of Engineering Science, Shanghai, China, ${ }^{8}$ Department of Radiology, The Third Affiliated Hospital of Southern Medical University, Guangzhou, China

Magnetic resonance imaging (MRI) could be the ideal diagnostic modality for early rheumatoid arthritis (RA). Vascular cell adhesion molecule-1 (VCAM-1) is highly expressed in synovial locations in patients with RA, which could be a potential target protein for RA diagnosis. The peptide VHPKQHR (VHP) has a high affinity to VCAM-1. To make the contrast agent to target $\mathrm{RA}$ at an early stage, we used VHP and ultrasmall paramagnetic iron oxide (USPIO) to synthesize UVHP ( $U$ stands for USPIO) through a chemical reaction with 1-(3dimethylaminopropyl)-3-ethylcarbodiimide hydrochloride and $\mathrm{N}$-hydroxysuccinimide. The size of UVHP was $6.7 \mathrm{~nm}$; the potential was $-27.7 \mathrm{mV}$, and the $r_{2} / r_{1}$ value was 1.73 . Cytotoxicity assay exhibited that the cell survival rate was higher than $80 \%$ at even high concentrations of UVHP (Fe concentration $200 \mu \mathrm{g} / \mathrm{mL}$ ), which showed the UVHP has low toxicity. Compared with no TNF- $\alpha$ stimulation, VCAM-1 expression was increased nearly 3fold when mouse aortic endothelial cells (MAECs) were stimulated with $50 \mathrm{ng} / \mathrm{mL}$ TNF- $\alpha$; cellular Fe uptake was increased very significantly with increasing UVHP concentration under TNF- $\alpha$ treatment; cellular Fe content was 17 times higher under UVHP with Fe concentration $200 \mu \mathrm{g} / \mathrm{mL}$ treating MAECs. These results indicate that UVHP can target overexpression of VCAM-1 at the cellular level. RA mice models were constructed with adjuvant-induced arthritis. In vivo $\mathrm{MRI}$ and biodistribution results show that the signal intensity of knee joints was increased significantly and Fe accumulation in RA model mice compared with normal wild-type mice after injecting UVHP $24 \mathrm{~h}$. These results suggest that we have synthesized a simple, lowcost, and less toxic contrast agent UVHP, which targeted VCAM-1 for early-stage RA diagnosis and generates high contrast in $\mathrm{T}_{1}$-weighted MRI.

Keywords: rheumatoid arthritis, magnetic resonance imaging, USPIO, VCAM-1, UVHP 


\section{INTRODUCTION}

Rheumatoid arthritis (RA), a chronic systemic immune disease (Firestein, 2003), has a global prevalence of $0.5 \%$ to $1 \%$ (AbdelNasser et al., 1997; Kvien, 2004). Early diagnosis and correct treatment can effectively alleviate the incidence of RA patients (Luo et al., 2018). Conventional radiography, computed tomography, ultrasonography, and magnetic resonance imaging (MRI) are common imaging methods for RA (Østergaard et al., 2008). Because of the high resolution of the tissue, MRI may be one of the most ideal methods used clinically for the early diagnosis of RA (Østergaard et al., 2008; Hou et al., 2020).

MRI contrast agents are divided into longitudinal relaxation contrast agents $\left(\mathrm{T}_{1}\right.$-weighted contrast agents) and transverse relaxation contrast agents ( $\mathrm{T}_{2}$-weighted contrast agents) according to their principle of action (Zhao et al., 2021). $\mathrm{T}_{1^{-}}$weighted contrast agent shortens the longitudinal relaxation time of the tissue and enhances the signal; $\mathrm{T}_{2}$-weighted contrast agent shortens the transverse relaxation time of the tissue and weakens the signal. As the $T_{2}$ signal is dark, and $T_{1}$ is a bright signal, and the high magnetic moment of the $\mathrm{T}_{2}$ contrast agent may cause magnetic-susceptibility artifacts ( $\mathrm{Na}$ et al., 2009; Zhou et al., 2020), and human vision prefers bright signals; $T_{1}$ contrast agent is more prevalently used than $\mathrm{T}_{2}$ in a clinical setting.

Commonly used clinical $\mathrm{T}_{1}$ contrast agents include Gd-DTPA (gadopentetate meglumine) (Carr et al., 1984), Gd-DOTA (Dotarem) (Meyer et al., 1988), and other Gd-type contrast agents, and Mn-DPDP (mangafodipir) (Jynge et al., 2020), $\mathrm{MnCl}_{2}$, and other Mn contrast agents. However, these contrast agents are not selective, and Gd-based contrast agents may be nephrotoxic (Prince et al., 2008). Because contrast agents can improve the sensitivity of MRI (Caravan, 2006), it is necessary to find a contrast agent for early targeted diagnosis of RA.

Superparamagnetic iron oxide nanoparticles (SPIO) and ultrasmall SPIO (USPIO) are $\mathrm{T}_{2}$ contrast agents that have been used in the clinic (Zhao et al., 2021). USPIO exhibits a decrease in magnetization due to the spin tilt effect as the particle size decreases, which effectively shortens the $T_{1}$ relaxation time of water protons. So, the USPIO can be used to improve $\mathrm{T}_{1^{-}}$ weighted MRI signals (Chen et al., 2020). USPIO with a particle size of less than $5 \mathrm{~nm}$ has received more and more attention from researchers as MRI $\mathrm{T}_{1}$ contrast agents (Zhou et al., 2020).

Simon et al. compared the imaging performance of $3.0 \mathrm{~nm}$ USPIO coated with carboxyl glucose and GD-DTPA for arthritis. The study shows that USPIO has a higher blood half-life and a more significant $T_{1}$ contrast (Simon et al., 2006). Li et al. designed a $\mathrm{T}_{1} / \mathrm{T}_{2}$-weighted contrast agent light-addressable ultrasmall $\mathrm{Fe}_{3} \mathrm{O}_{4}$ nanoparticles, which targeted macrophages in arthritis by folic acid. After $405-\mathrm{nm}$ laser irradiation, the nanoparticle forms nanoclusters leading to $T_{1}$-weighted MRI change into $T_{2^{-}}$ weighted MRI (Li et al., 2019).

The specific mechanism of RA is currently unknown, but many clinical phenotypes of RA have been reported, including inflammatory factors (such as tumor necrosis factor- $\alpha$ [TNF- $\alpha$ ] and interleukin-8) in the joint environment of RA patients; these inflammatory factors lead to the vascular cell adhesion molecule1 (VCAM-1) overexpression in the synovium around the joint. Overexpression VCAM-1 was observed in fibroblast-like synoviocytes and endothelial cells (Elices et al., 1992; Dolati et al., 2016). VHPKQHR (VHP) is a peptide targeted to VCAM-1 identified by phage display technology and has been applied to target atherosclerotic plaque (Nahrendorf et al., 2006; Xu et al., 2019), but the use of VHP combined with USPIO for RA targeted imaging has not been reported yet.

This study synthesized a $\mathrm{T}_{1}$-weighted MRI contrast agent UVHP (USPIO combined with VHP) that can target RA. Because of its low cost, simple method, and low toxicity, UVHP has the potential for clinical application.

\section{MATERIALS AND METHODS}

\subsection{Synthesis and Characterization of USPIO and UVHP}

\subsubsection{Synthesis of USPIO}

Synthesis of USPIO by the method provided in the published research article (Luo et al., 2015) was performed as follows: sodium citrate (final concentration $45.60 \mathrm{mM}$ ) was added to $80 \mathrm{~mL}$ of homogeneous $\mathrm{FeCl}_{3}$ solution (dissolved in the final concentration of diethylene glycol $81.77 \mathrm{mM}$ ) in a water bath at $80^{\circ} \mathrm{C}$ until a clarified solution was formed. Subsequently, sodium acetate (final concentration $299.06 \mathrm{mM}$ ) was added to the above mixture and dissolved, and then the mixture was transferred to a 100-mL Teflon-lined stainless-steel autoclave reactor and sealed. The autoclave was placed in an oven at $200^{\circ} \mathrm{C}$ for $4 \mathrm{~h}$. After cooling to room temperature, the black precipitate was collected by centrifugation $(13,200 \mathrm{~g}, 15 \mathrm{~min})$. Precipitation was washed three times with ethanol to remove excess reactants and byproducts then were dissolved in $10 \mathrm{~mL} \mathrm{ddH_{2 }} \mathrm{O}$ and lyophilized to obtain $460 \mathrm{mg}$ powder for the next step.

\subsubsection{Synthesis of UVHP}

USPIO $\left(100 \mathrm{mg}\right.$ ) was dissolved in $18 \mathrm{~mL}$ of $\mathrm{ddH}_{2} \mathrm{O}$ at room temperature. 1-(3-Dimethylaminopropyl)-3-ethylcarbodiimide (molecular weight $[\mathrm{MW}]=192$; Shanghai Yuanye BioTechnology Co., Ltd.) in $1 \mathrm{~mL} \mathrm{ddH}_{2} \mathrm{O}$ (final concentration $0.047 \mathrm{M}$ ) and $\mathrm{N}$-hydroxysuccinimide ( $\mathrm{MW}=115.8$; Shanghai Yuanye Bio-Technology Co., Ltd.) in $1 \mathrm{~mL} \mathrm{H}_{2} \mathrm{O}$ (final concentration $0.03 \mathrm{M}$ ) were added to the reaction solution and activated by vigorous stirring under ice bath conditions for $6 \mathrm{~h}$. The peptide (VHPKQHR, Sangon Biotech [Shanghai] Co., Ltd.) $20 \mathrm{mg}(\mathrm{MW}=1,081)$ was added and reacted for $6 \mathrm{~h}$ under an ice bath. The reaction was carried out with a dialysis membrane (MW cutoff $=1,500$ ) in phosphate-buffered saline (PBS, three times, $2 \mathrm{~L}$ ) and $\mathrm{ddH}_{2} \mathrm{O}$ (six times, $2 \mathrm{~L}$ ) to dialyze the mixture for 3 days under an ice bath to remove unreacted excess reactants. After freeze-drying, $83.4 \mathrm{mg}$ UVHP was obtained (U stands for USPIO, VHP stands for VHPKQHR).

\subsubsection{Characterization of Nanoparticles}

Fourier transform infrared (FTIR) spectra were measured on a Bio-Rad FTS 6000 spectrometer (Bio-Rad Company, Hercules, 
CA, USA) at $25^{\circ} \mathrm{C}$ (Li et al., 2020). Thermogravimetry (TGA) curves were carried out using a NETZSCH thermal analyzer (DSC 204F1) at a heating rate of $10^{\circ} \mathrm{C} / \mathrm{min}$ in a nitrogen atmosphere (Yu et al., 2015). Zeta potential and dynamic light scattering (DLS) measurements were conducted using a Malvern Zetasizer Nano ZS (Malvern Instruments) (Li et al., 2020). The morphology and size of USPIO and UVHP were characterized by a field emission $2100 \mathrm{~F}$ transmission electron microscope (TEM; JEOL, Japan) under $200-\mathrm{kV}$ acceleration voltage (Yang et al., 2021). One-tesla MRI scanner (NM42-040H-I, Niumag, China) was used to measure the $r_{1}$ and $r_{2}$ values of USPIO and UVHP. The Fe contents of USPIO and UVHP were detected by ICP-OES (inductively coupled plasma optical emission spectrometer; Thermo E. IRIS Duo) (Tao et al., 2019). For example, we weighed 2,000 $\mu \mathrm{g}$ UVHP, and after measuring with ICP-OES, the Fe content was $262 \mu \mathrm{g}$. According to this result, we can weigh the corresponding UVHP amount according to the Fe content required by our experiments (Supplemental data). $T_{1}$ relaxometry and $\mathrm{T}_{2}$ relaxometry were performed by a $0.5-\mathrm{T}$ NMR analyzer (MINIPQ001; Shanghai Niumag Co., China).

\subsection{Material, Cell Cultivation, and Sample Processing \\ 2.2.1 Cell Material and Culture}

Mouse aortic endothelial cells (MAECs) were purchased from CHI Scientific, Inc. Raw 264.7 cell line was obtained from ATCC (American Type Culture Collection). Human fibroblast-like synoviocyte RA (HFLS-RA) cell line was purchased from Guangzhou Jennio-bio Co., Ltd. (Guangzhou, China). MAECs, HFLS-RA cells, and raw 264.7 cells were grown in Dulbecco modified eagle medium (DMEM) medium containing $10 \%$ fetal bovine serum and $1 \%$ penicillin-streptomycin at $37^{\circ} \mathrm{C}$ in a humidified atmosphere with $5 \% \mathrm{CO}_{2}$.

\subsubsection{Animal Model and Culture}

Two-month-old female C57BL/6 mice were purchased from Animal Experimental Center, Southern Medical University. The mice had free access to food and water under a 12-h light/12-h dark cycle. All animal experiments were approved by the Institutional Animal Ethics Committee of South China Normal University and were carried out following the National Institutes of Health Guidelines for the Care and Use of Laboratory Animals of South China Normal University.

C57BL/6 mice were used to construct RA model mice. Complete Freund's adjuvant was mixed with $2 \%$ methylated bovine serum albumin (mBSA) in equal volume and injected into the axillae of 2-month-old female C57BL/6 mice at $0.1 \mathrm{~mL}$ per side. Three weeks later, $2 \%$ mBSA solution (dissolved in sterile water) was injected into the joint cavity of mice at $10 \mu \mathrm{L}$ per side (Jones et al., 2018). Two months later, RA model (antigen-induced arthritis) mice were molded. In animal experiments, C57BL/6 mice of the same sex and age were used as wild-type (WT) mice. RA model mice identification: RA model mice $(n=3)$ were euthanized, and the knee joints were fixed with formalin and were sent to Servicebio (Wuhan, China) for hematoxylin and eosin (H\&E) staining, with
C57BL/6 mice $(n=3)$ as controls. Safranin O/fast green (safranin/O) staining was carried out with the modified Safranin O-Fast Green FCF Cartilage Stain Kit (Solarbio, Beijing, China). The histological scoring of the sections was performed by three unwitting researchers using the Mankin scoring system. According to the classification of Mankin and his colleagues, the score is divided into four stages: near normal (0-2), early (2-6), middle (6-10), and late (10-14) (Iannitti et al., 2013; Nishitani et al., 2014).

\subsubsection{Hemolytic Assay}

Fresh blood from 8-week-old C57BL/6 mice is added to a tube containing sodium heparin. The erythrocyte was collected by centrifugation at $650 \mathrm{~g}$ for $10 \mathrm{~min}$. Then, erythrocyte was diluted to $0.25 \%$ with PBS ( $\mathrm{pH} 7.4$ ) and incubated with different concentrations of UVHP (Fe concentration 12.5, 25, 50, 100, $200 \mu \mathrm{g} / \mathrm{mL}$ ) at $37^{\circ} \mathrm{C}$ for $12 \mathrm{~h}$. Erythrocyte diluted with deionized water was used as a negative control, and erythrocyte diluted with PBS was used as a positive control. After $12 \mathrm{~h}$ of treatment, each group was centrifuged at $10,000 \mathrm{~g}$ for $5 \mathrm{~min}$, and $200 \mu \mathrm{L}$ of supernatant was placed in a 96-well plate. The absorbance at $542 \mathrm{~nm}$ was measured using a microplate reader (INFINITE M200, Tecan, Switzerland). Each group was repeated three times.

\subsubsection{Cytotoxicity Assay}

The cytotoxicity of UVHP on RAW264.7 and HFLS-RA cells was investigated by the Cell Counting Kit-8 (CCK-8; Dojindo Laboratories, Kumamoto, Japan) method. The cells were inoculated at a cell density of $1 \times 10^{4}$ per well in 96-well plates and were cultured for $12 \mathrm{~h}$ or $24 \mathrm{~h}$ with a fresh medium containing different concentrations of UVHP (Fe concentration $0,5,10,25,50,100,150,200 \mu \mathrm{g} / \mathrm{mL})$ instead of nutrient-depleted medium, followed by $2 \mathrm{~h}$ with fresh serum-free medium containing $10 \%$ CCK- 8 . The absorbance at $450 \mathrm{~nm}$ in each well was measured using a microplate reader (INFINITE M200, Tecan, Switzerland); cell viability was calculated according to the instructions. All experiments were performed three times in parallel.

\subsubsection{Toxicity Evaluation}

The UVHP (Fe content $150 \mu \mathrm{g}$, dissolved in $100 \mu \mathrm{L}$ PBS) was injected into RA mice $(n=3)$ through the tail vein. After 14 days, organs (heart, liver, spleen, lungs, kidneys) were collected from the mice. Sections and H\&E staining were obtained from Servicebio (Wuhan, China) after $24 \mathrm{~h}$ of fixation with formalin. The RA mice $(n=3)$ injected with saline served as controls.

\subsubsection{Western Blot}

We treated MAECs with TNF- $\alpha$ (Abbkine Scientific Co., Ltd.) at concentrations of 10 and $50 \mathrm{ng} / \mathrm{mL}$ for $24 \mathrm{~h}$ (Fan et al., 2019); the cell culture medium was removed and washed three times with PBS. The cells were lysed by adding cell lysate on ice for $30 \mathrm{~min}$ and then quickly scraped with a clean cell scraper. Cell debris and lysate were centrifuged at $13,200 \mathrm{~g}$ for $20 \mathrm{~min}$, and then the supernatant was collected. Protein samples were denatured and separated on sodium dodecyl sulfate-polyacrylamide gels 


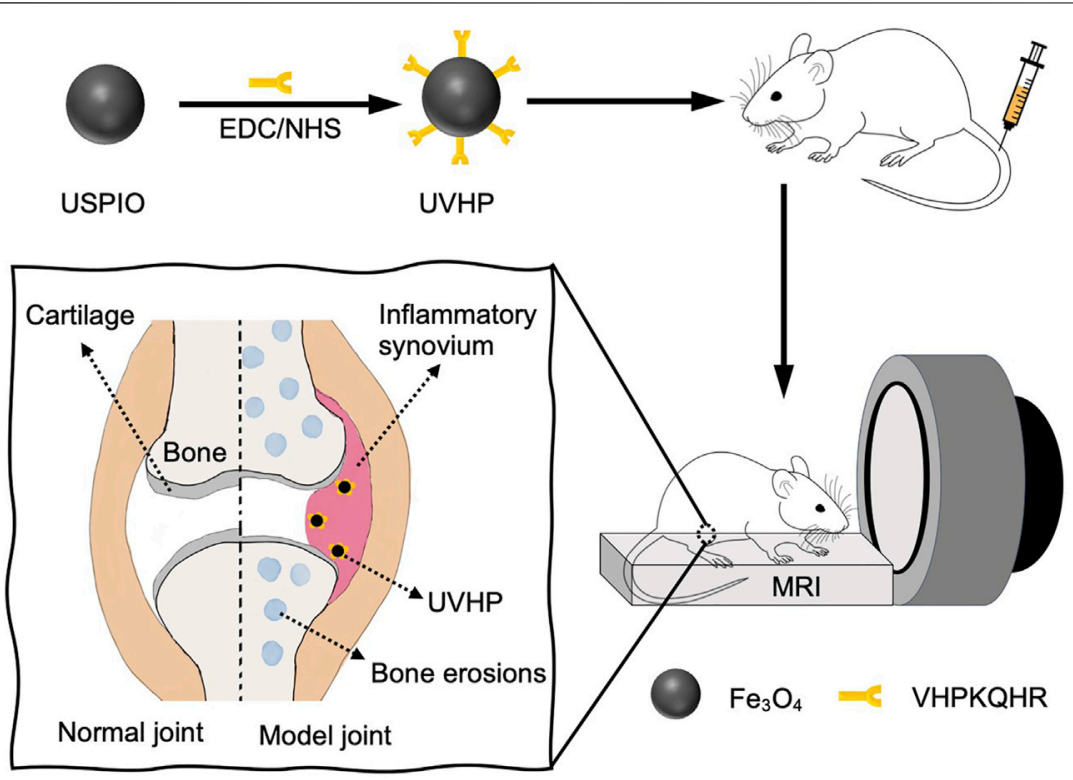

FIGURE 1 | Schematic illustration of the preparation and targeting rheumatoid arthritis of UVHP

and then transferred to polyvinylidene difluoride membranes (cat. no.: IPVH00010 PORE SIZE: $0.45 \mu \mathrm{m}$; Merck Millipore Ltd.). The membranes were blocked with TBST solution ( $150 \mathrm{mM} \mathrm{NaCl}, 10 \mathrm{mM}$ Tris-HCl, $\mathrm{pH}$ 7.4, $0.1 \%$ Tween 20 ) containing $5 \%$ skim milk for $2 \mathrm{~h}$, followed by incubation with specific primary antibody (anti-VCAM-1 polyclonal antibody, Servicebio; anti-GAPDH [GAPDH was used as loading control], Absin, Shanghai, China) and secondary antibody (goat antirabbit immunoglobulin G [IgG, corresponding to VCAM-1]; MultiSciences, Hangzhou, China; goat anti-mouse IgG [corresponding to GAPDH], Dingguo, Beijing, China). Signals were detected using an image analyzer (Tanon-5200, Shanghai, China). The experiment was repeated three times, and results were analyzed using ImageJ software.

\subsubsection{The In Vivo Biodistribution of UVHP}

The mice after scanning with MRI were euthanized, and the organs heart, liver, spleen, lungs, kidneys, and knee joints were extracted and weighed, respectively. They were cut into small pieces of 1 to $2 \mathrm{~mm}$ and digested with aqua regia solution for $24 \mathrm{~h}$, and then ICP-OES was used to detect the Fe content of different organs (Hou et al., 2020).

\subsubsection{Cell Targeting MRI Experiment of UVHP}

Cells (MAECS or HFLS-RA cells) were seeded at $1 \times 10^{5}$ cells per well in six-well plates with DMEM, and TNF- $\alpha(50 \mathrm{ng} / \mathrm{mL}$ for MAECs and $10 \mathrm{ng} / \mathrm{mL}$ for HFLS-RA [Croft et al., 1999]) or the same volume of PBS (as a control) was added, respectively. After $24 \mathrm{~h}$ of incubation, DMEM containing USPIO, UVHP (both Fe $50 \mu \mathrm{g} / \mathrm{mL}$ ), or DMEM (as a control) replaced the original cell culture medium, treatment for $24 \mathrm{~h}$. Raw 264.7 cells were also seeded at $1 \times 10^{5}$ cells per well in six-well plates with DMEM. After $24 \mathrm{~h}$, DMEM containing USPIO, UVHP (both Fe $50 \mu \mathrm{g}$ /
$\mathrm{mL}$ ), or DMEM (as a control) was used to replace the original cell culture medium for $24 \mathrm{~h}$ of treatment. The cells were washed three times with PBS to remove USPIO/UVHP that were not phagocytosed by the cells and then collected by trypsin and dispersed in $0.5 \mathrm{~mL}$ agarose (1\%). MRI scan was obtained with a Philips $3.0 \mathrm{~T}$ Achieva MRI system (Healthcare, Best, the Netherlands), with the following scan parameters: FOV (field of view) $=60 \times 60 \mathrm{~mm}, \quad$ matrix $=256 \times 256$, slice thickness $=2 \mathrm{~mm}$, TR (time of repetition) $=1,200 \mathrm{~ms}$, and TE (time of echo) $=17 \mathrm{~ms}$.

\subsubsection{Cell Targeting Quantitative Determination Experiment of UVHP}

Cells (MAECS or HFLS-RA cells) were seeded in six-well plates at a density of $1 \times 10^{5}$ and treated with TNF- $\alpha(50 \mathrm{ng} / \mathrm{mL})$ for $24 \mathrm{~h}$. The culture medium was replaced by a fresh culture medium containing UVHP (Fe concentration 25, 50, 100, and $200 \mu \mathrm{g} / \mathrm{mL}$ ) and incubated for $24 \mathrm{~h}$. The cells were washed three times with $1 \mathrm{~mL}$ PBS to remove the UVHP that were not taken up by the cells and then trypsinized and collected by centrifugation. The cells were resuspended with $1 \mathrm{~mL}$ PBS; the number of cells per well was counted, and then the cells were digested with aqua regia (Luo et al., 2015). ICP-OES was used to detect the Fe content of MAECs. For comparison, the same experiments were performed with cells (MAECS or HFLS-RA cells) treated with PBS (instead of TNF- $\alpha$ ) for $24 \mathrm{~h}$, and the subsequent UVHP treatment of cells and other operations are the same.

\subsubsection{In Vivo MRI of UVHP Targeting RA}

The knee joints of RA mice $(n=3)$ and C57BL/6 mice $(n=3)$ were scanned with a 7-T MRI (Bruker Biospec $7 \mathrm{~T}$ ), with the following scan parameters: $\mathrm{TR}=900, \quad \mathrm{TE}=9 \mathrm{~ms}$, 
A

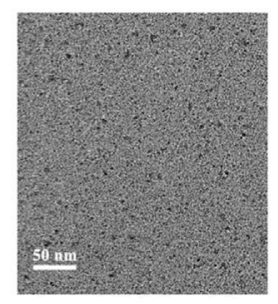

$\mathrm{E}$

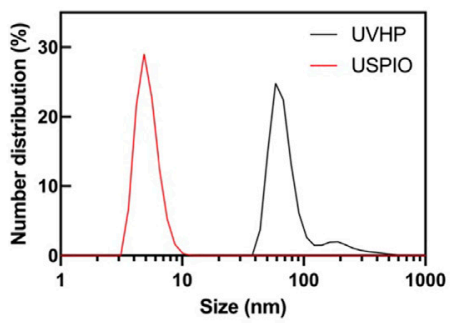

B

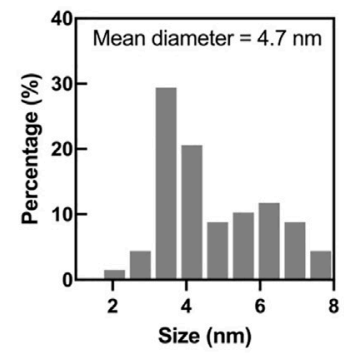

$\mathbf{F}$

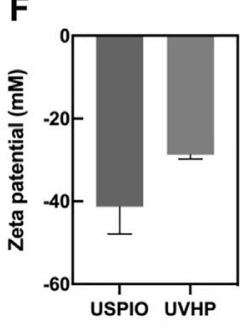

C

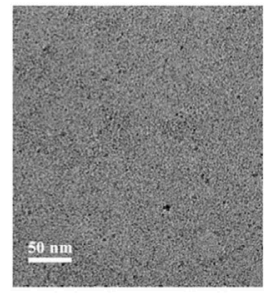

D
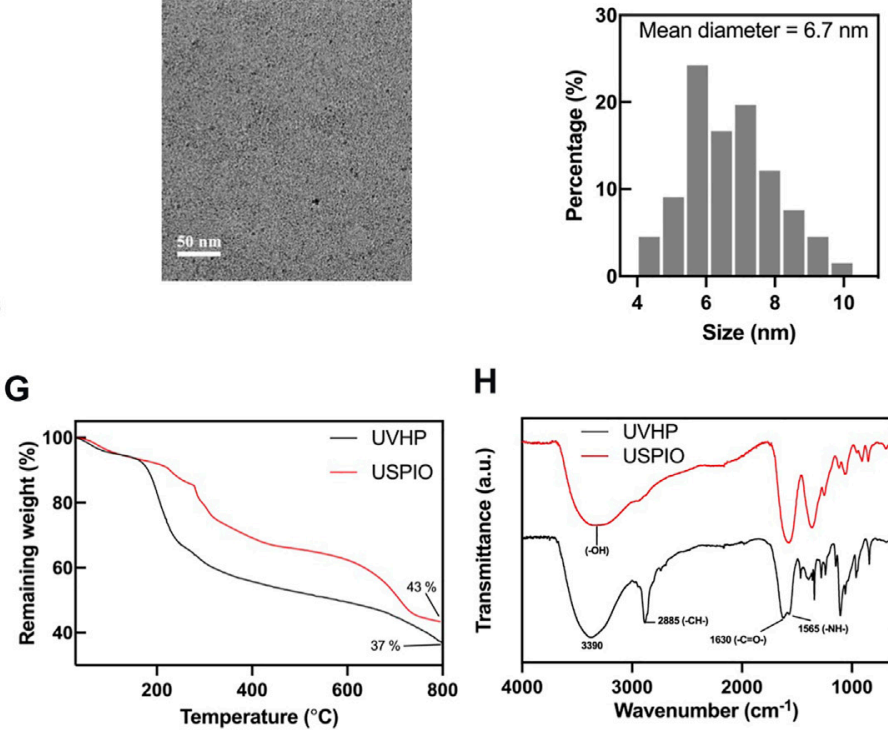

H

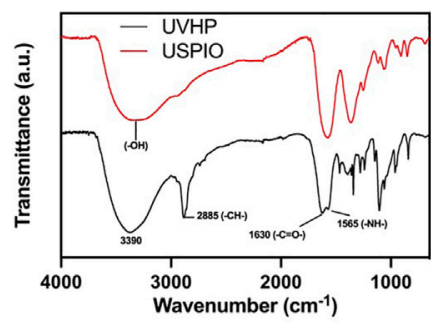

FIGURE 2 | Characterizations of USPIO and UVHP. (A) TEM image of USPIO; (B) size distribution histogram of USPIO; (C) TEM image of UVHP; (D) size distribution histogram of UVHP; (E) hydrodynamic sizes of USPIO and UVHP; (F) zeta potentials of USPIO, UVHP; (G) TGA curves of USPIO, UVHP; (H) FTIR spectra of USPIO, UVHP.

FOV $=80 \times 80 \mathrm{~mm}, \quad$ matrix $=256 \times 256, \quad$ ST $\quad$ (slice thickness) $=1 \mathrm{~mm}$.

Two groups of RA mice $(n=3)$ were selected and injected with USPIO, UVHP (both Fe content $150 \mu \mathrm{g}$, dissolved in $100 \mu \mathrm{L}$ PBS) in the tail vein, respectively. Two groups of C57BL/6 mice $(n=3)$ were selected and treated with the same conditions as controls. The mice were scanned after injecting UVHP for $24 \mathrm{~h}$. $\mathrm{T}_{1}$-weighted imaging was performed with a 7-T MRI scanner (Bruker Biospec $7 \mathrm{~T}$ ). Scan parameters were as follows: $\mathrm{TR}=1,000, \mathrm{TE}=8.5 \mathrm{~ms}$, $\mathrm{FOV}=80 \times 80 \mathrm{~mm}$, matrix $=256 \times 160, \mathrm{ST}=1 \mathrm{~mm}$. For image analysis, all images were analyzed via MRI viewing station (Paravision 5.1; Bruker, Karlsruhe, Germany).

\subsubsection{Statistical Analysis}

The significant difference of the experimental data was performed by one-way analysis-of-variance statistical analysis. When $p<0.05$, the values were considered to be statistically significantly different. $p<0.05$ is represented by $\left(^{*}\right), p<0.01$ is represented by $\left({ }^{* *}\right)$, and $p<0.001$ is represented by $\left({ }^{* *}\right)$.

\section{RESULTS}

\subsection{Synthesis and Characterization of USPIO and UVHP}

We synthesized surface carboxylated USPIO according to the articles by Chen et al. (2020) and Luo et al. (2015) (for more details, see Materials and Methods). After that, we linked peptides VHP and USPIO together with an amide bond to form UVHP (Figure 1) (for more details, see Materials and Methods). TEM was used to characterize the size and morphology of USPIO and UVHP
(Figures 2A,C). The size distribution histogram showed that the mean diameter of the USPIO was $4.7 \pm 2.76 \mathrm{~nm}$ (Figure 2B); the zeta potential was $-40 \mathrm{mV}$. Compared with USPIO, the particle size of the UVHP increased to $6.69 \pm 2.78 \mathrm{~nm}$ (Figure 2D), and the zeta potential changed to $-27.7 \mathrm{mV}$ (Figure 2F), which should be attributed to the VHP connecting to the USPIO surface. DLS analysis showed that the hydrodynamic sizes of USPIO and UVHP were approximately 4 and $60 \mathrm{~nm}$, respectively (Figure 2E). The increase in the hydrodynamic size of UVHP may be due to the decrease in the surface potential of the particles after the VHP was connected, which reduced the repulsion between the particles (Liu et al., 2013).

The combination of peptide VHP with USPIO was further confirmed by Fourier FTIR. As shown in Figure $\mathbf{2 H}$, the absorption peaks in FTIR spectra at $3,390 \mathrm{~cm}^{-1}, 2,885 \mathrm{~cm}^{-1}$, $1,630 \mathrm{~cm}^{-1}$, and $1,565 \mathrm{~cm}^{-1}$ represent the $\mathrm{O}-\mathrm{H}, \mathrm{C}-\mathrm{H}$, and $\mathrm{N}-\mathrm{H}$ stretching of UVHP, which could be attributed to the successful connection VHP with USPIO. The VHP conjugated to the surface of USPIO was quantitatively characterized by TGA (Figure 2G). The USPIO had a weight loss of 57\% (Figure 2G), which should be attributed to the citrate on the particle surface. The weight loss of UVHP was $63 \%$ after modification with the peptide VHP. The above results indicate that we successfully synthesized UVHP.

\section{2 $\mathrm{T}_{1}$ and $\mathrm{T}_{2}$ Relaxometry and MRI of USPIO and UVHP}

To test the potential of UVHP in MRI application, we monitor the MRI signal intensity of $\mathrm{T}_{1}$-weighted $\mathrm{MRI}$ and $\mathrm{T}_{2}$-weighted MRI of USPIO and UVHP using a 3.0-T clinical MRI system. The MRI 
A

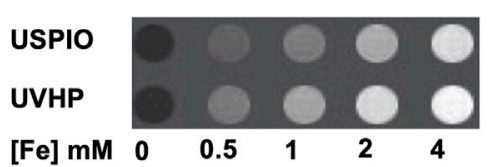

B

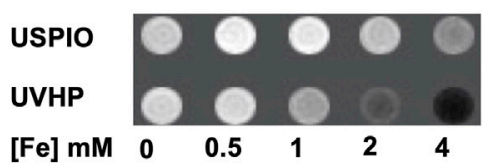

E

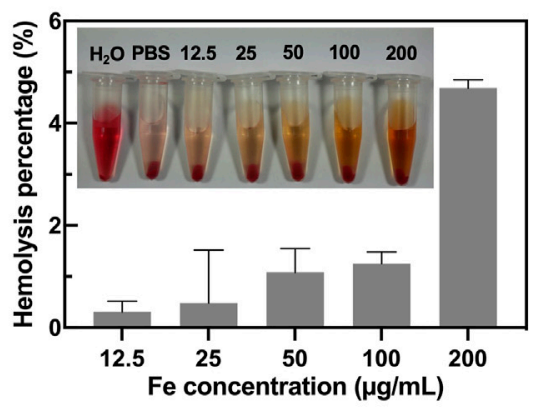

C

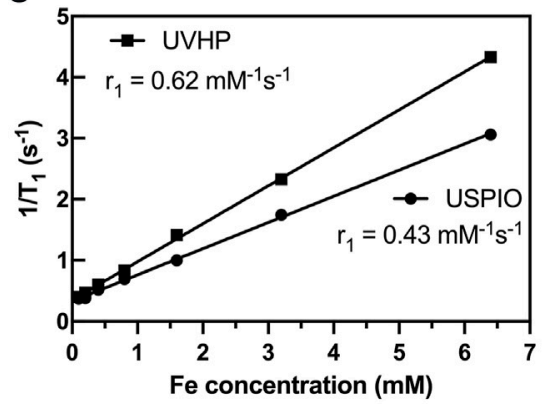

$\mathbf{F}$

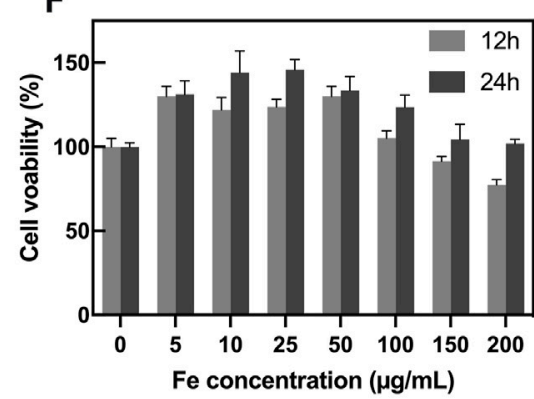

D

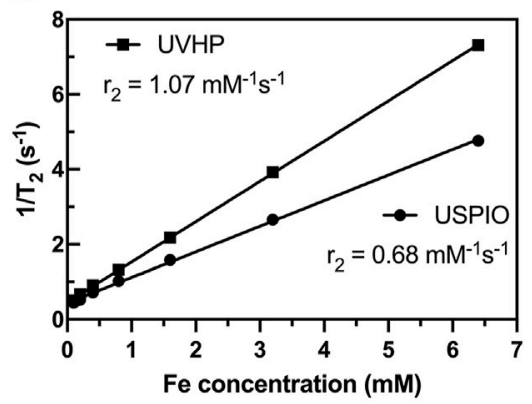

G

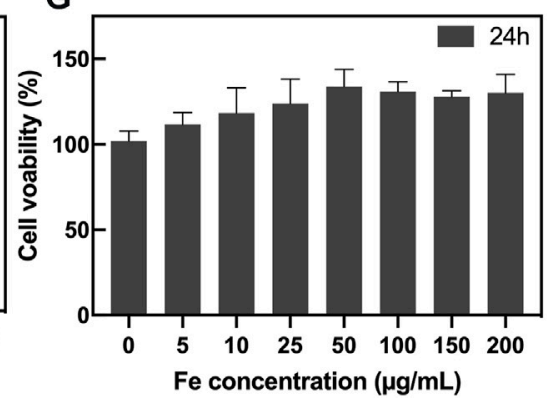

FIGURE 3 | MRI scans and cytotoxicity assay of UVHP. $T_{1}$-weighted (A) and $T_{2}$-weighted (B) images of UVHP aqueous solution at different Fe concentrations (0, $0.5,1,2$, and $4 \mathrm{mM}$ ) taken by a 3.0-T clinical MRI system under the following parameters: FOV = $100 \mathrm{~mm}$; matrix = 168 $\times 168 ;$ section thickness = 2 mm; TR = 2,000 ms; $\mathrm{TE}=60 \mathrm{~ms}$. USPIO was used as control. (C,D) Plot of $1 / \mathrm{T}_{1}$ and $1 / \mathrm{T}_{2}$ over Fe concentration of UVHP, the slope indicates the specific relaxivity $\left(r_{1}\right.$ and $\left.r_{2}\right)$. USPIO was used as control. (E) The hemolysis assay of UVHP (Fe concentration 12.5, 25, 50, 100, $200 \mu \mathrm{g} / \mathrm{mL}$ ). PBS and water were used as negative and positive controls. (F) The viability of RAW 264.7 cells after coculture with UVHP at different Fe concentrations for 12 or 24 h was measured by the CCK8 assay. RAW 264.7 cells treated with PBS were used as control, respectively. (G) The viability of HFLS-RA cells after coculture with UVHP at different Fe concentrations for 24 h was measured by the CCK8 assay. HFLS-RA cells treated with PBS were used as control, respectively.

results (Figure 3A) showed that as the Fe concentration increased, the $\mathrm{T}_{1}$-weighted MRI scan became brighter, and UVHP would be slightly brighter than USPIO under the same Fe concentration. The $\mathrm{T}_{2}$-weighted MRI (Figure 3B) showed that the image became darker as the Fe concentration increased; UVHP would be slightly darker compared with USPIO under the same Fe concentration (Figure 3B). Furthermore, when picking relaxation rate $\left(1 / \mathrm{T}_{1}\right.$ or $\left.1 / \mathrm{T}_{2}\right)$ as the ordinate and $\mathrm{Fe}$ concentration as the abscissa, Fe concentration is linearly proportional to the value of $1 / \mathrm{T}_{1}$ or $1 / \mathrm{T}_{2}$ (Luo et al., 2015), and their slope was the longitudinal relaxation rate $r_{1}$ and transverse relaxation rate $r_{2}$ values of USPIO and UVHP, respectively (Figures 3C, D). The $r_{1}$ and $r_{2}$ values of USPIO were 0.43 and $0.68 \mathrm{mM}^{-1} \mathrm{~s}^{-1}$, respectively; the $r_{2} / r_{1}$ ratio was 1.58 . As for UVHP, the $r_{1}$ and $r_{2}$ values were 0.62 and $1.07 \mathrm{mM}^{-1} \mathrm{~s}^{-1}$, respectively; the $r_{2} / r_{1}$ ratio was $1.73 . \mathrm{T}_{1}$ contrast agent should have a high $r_{1}$ relaxation rate and low $r_{2} / r_{1}$ value, and theoretically, $r_{2} / r_{1}$ value in the range of 1 to 2 should be suitable for T1-weighted MRI (Tromsdorf et al., 2009). Combining $\mathrm{T}_{1}$-weighted MRI and the value of $r_{2} / r_{1}$, USPIO and UVHP could be used as a potential $\mathrm{T}_{1}$-weighted imaging contrast agent in the future.

\subsection{Hemolysis and Cytotoxicity Assay of UVHP}

Hemolytic assay was used to investigate the hemocompatibility of the UVHP. As shown in Figure 3E, there was no significant hemolysis phenomenon observed for blood cells treated with
UVHP with Fe concentrations of $12.5,25,50,100$, and $200 \mu \mathrm{g} /$ $\mathrm{mL}$. Further quantitative analysis showed that the hemolytic percentages of UVHP (Fe concentrations $0-200 \mu \mathrm{g} / \mathrm{mL}$ ) were all lower than 5\% (a threshold value) (Hu et al., 2015).

The cytotoxicity of UVHP was evaluated by CCK-8 before in vivo biomedical applications (Figure 3F). After incubation with the UVHP at Fe concentrations of $0,5,10,25,50,100,150$, and $200 \mu \mathrm{g} / \mathrm{mL}$ for $12 \mathrm{~h}$, the cell viability of RAW264.7 was approximately $80 \%$ at $200 \mu \mathrm{g} / \mathrm{mL} \mathrm{Fe}$ concentration. Most investigators chose $80 \%$ as the threshold for cytotoxicity (Chen et al., 2020). Next, we extended the treatment time to $24 \mathrm{~h}$; as Figure 3F shows, the cell survival rate was still greater than $80 \%$ when $\mathrm{Fe}$ concentration was $200 \mu \mathrm{g} / \mathrm{mL}$. In order to further investigate the cytotoxicity of UVHP in RA, we incubated HFLS-RA cells with UVHP for $24 \mathrm{~h}$, and the result of cell viability (Figure 3G) was similar to that of RAW264.7 cells. These results indicate that UVHP had low toxicity and hemocompatibility in Fe concentration of 0 to $200 \mu \mathrm{g} / \mathrm{mL}$.

\subsection{UVHP Targeting Cells (MAECs or HFLS-RA Cells) of TNF- $\alpha$ Stimulation}

It has been previously reported that TNF- $\alpha$ is highly expressed in RA lesions (Choy and Panayi, 2001; da Costa Moura, 2013), and VCAM-1 overexpression was observed in MAECs under stimulation with TNF-a (Fan et al., 2019). So, we chose 


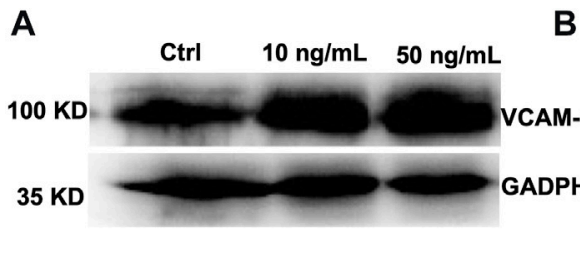

E

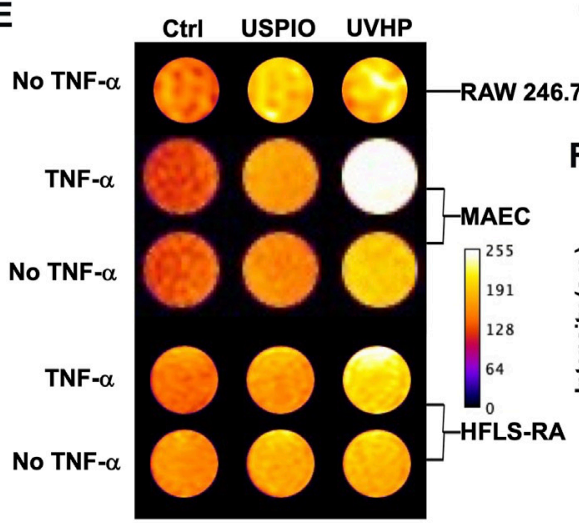

B

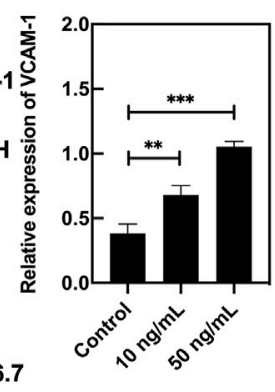

F

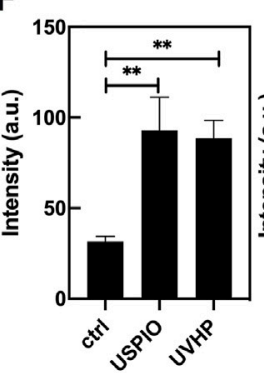

C

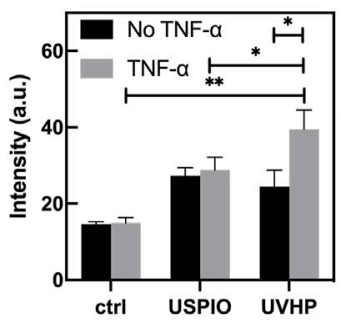

D
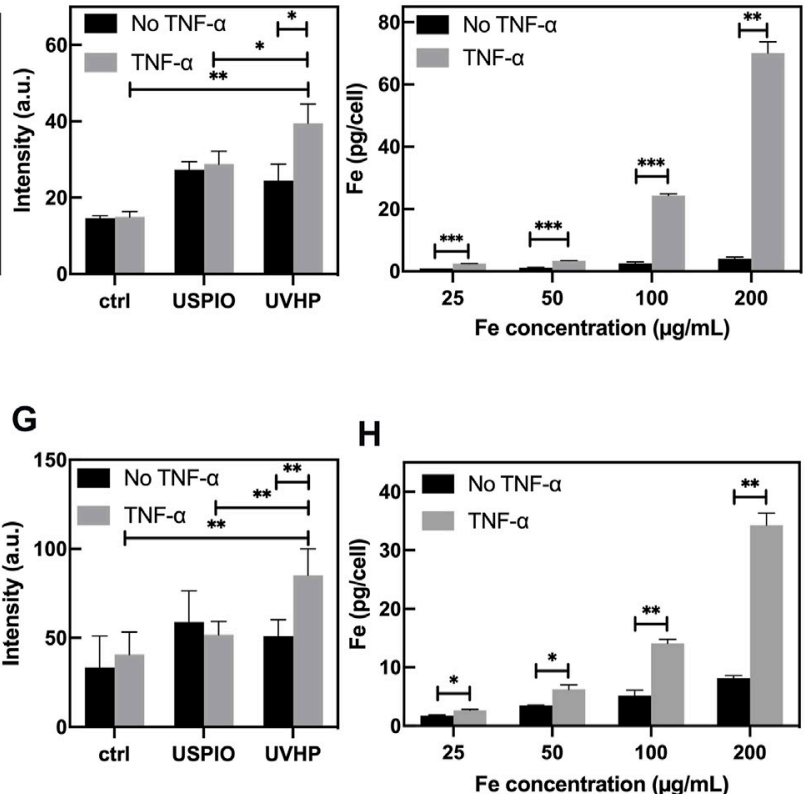

H

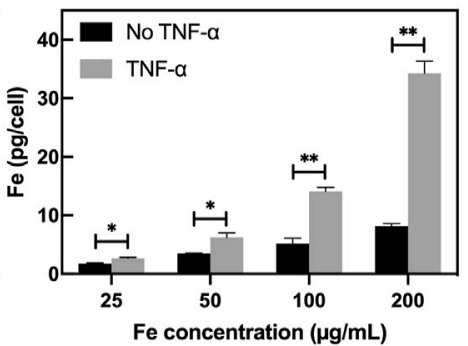

FIGURE 4 | TNF- $\alpha$-stimulated MAEC high expression of VCAM-1 and cell targeting assay. (A) Western blot of MAECs treated with TNF- $\alpha$ (10 ng/mL, 50 ng/mL). MAECs treated with PBS were used as control. (B) Quantitative Western blot analysis of VCAM-1. (C) $\mathrm{T}_{1}$-weighted MRI signal values of non-TNF- $\alpha$-stimulated MAECs and TNF- $\alpha$-stimulated MAECs treated with the USPIO and UVHP (both Fe concentration $50 \mu \mathrm{g} / \mathrm{mL}$ ). (D) The TNF- $\alpha-$ stimulated MAEC uptake of the UVHP with different concentrations (Fe concentration 25, 50, 100, and $200 \mu \mathrm{g} / \mathrm{mL}$ ) for $24 \mathrm{~h}$. No TNF- $\alpha$-stimulated MAECs were used as control. (E) T 1 -weighted MR pseudocolor

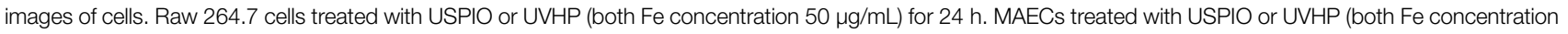
$50 \mu \mathrm{g} / \mathrm{mL}$ ) for $24 \mathrm{~h}$ in the presence or absence of TNF- $\alpha$ (50 ng/mL). HFLS-RA cells treated with USPIO or UVHP (both Fe concentration $50 \mu \mathrm{g} / \mathrm{mL}$ ) for $24 \mathrm{~h}$ in the presence or absence of TNF- $\alpha\left(10 \mathrm{ng} / \mathrm{mL}\right.$ ). All cells treated with PBS as controls. (F) $\mathrm{T}_{1}$-weighted MRI signal values of non-TNF- $\alpha-s t i m u l a t e d ~ r a w ~ 264.7$ cells treated with the USPIO and UVHP (both Fe concentration $50 \mu \mathrm{g} / \mathrm{mL}$ ). (G) T -weighted MRI signal values of non-TNF- $\alpha-$ stimulated HFLS-RA cells and TNF- $\alpha-$ stimulated HFLS-RA cells treated with the USPIO and UVHP (both Fe concentration $50 \mu \mathrm{g} / \mathrm{mL}$ ). (H) The TNF- $\alpha$-stimulated HFLS-RA cell uptake of the UVHP with different concentrations (Fe concentration 25, 50, 100, and $200 \mu \mathrm{g} / \mathrm{mL}$ ) for $24 \mathrm{~h}$. Non-TNF-a-stimulated HFLS-RA cells were used as control.

MAECs with TNF- $\alpha$ treatment to mimic the microenvironment at the site of arthritis. As shown in Figure 4A, compared with the MAECs treated with PBS (as control), the expression of VCAM-1 was increased after MAECs treated with TNF- $\alpha$ for $24 \mathrm{~h}$. The Western blot analysis demonstrated that VCAM-1 expression in MAECs was increased two and three times after 10 and $50 \mathrm{ng} / \mathrm{mL}$ TNF- $\alpha$ stimulation, respectively, comparing with the control (Figure 4B). These results confirm that TNF- $\alpha$ could increase the VCAM-1 expression in MAECs.

First, we used MRI to explore the effect of UVHP on RAW264.7 cells. After $24 \mathrm{~h}$ of UVHP or USPIO treatment, RAW264.7 cells were examined under $\mathrm{T}_{1}$-weighted MRI, and the signal intensity was counted (Figure 4E, first row). The results (Figure 4F) showed that there was no significant difference in the signal intensity between cells treated with UVHP and that, after USPIO treatment, both were higher than those of PBStreated cells.

In order to explore the ability of UVHP to target VCAM-1, we used UVHP to treat MAECs and HFLS-RA cells, respectively. As shown in Figure 4E, we set up a PBS experimental group and a TNF- $\alpha$ experimental group for each cell type, which treated them with PBS or TNF- $\alpha$ for $24 \mathrm{~h}$, respectively. Each group contained three different cell treatment subgroups: PBS, UVHP, or USPIO (both Fe concentration $50 \mathrm{ng} / \mathrm{mL}$ ); for $24 \mathrm{~h}$, the $\mathrm{T}_{1}$-weighted MRI signal intensity was counted (Figure 4E, second to fifth row). The signal of the statistical results is shown in Figure $4 \mathrm{C}$ and Figure 4G. In the PBS group (no TNF- $\alpha$ treatment), there was no significant difference in the signals after UVHP and USPIO treated MAECs and HFLS-RA cells, and both were higher than those treated with PBS. These results show that both USPIO and UVHP enhanced the T1-weighted signal strength, which are similar to the results of the RAW264.7 cells experiment above. In the TNF- $\alpha$ treatment group, the $\mathrm{T}_{1}$-weighted MRI signal after UVHP treatment was significantly higher than that of the USPIO group, and both were significantly higher than those treated with PBS. Because TNF- $\alpha$ stimulates cells (MAECs or HFLS-RA cells; Croft et al., 1999) to express VCAM-1, we can conclude from the results that UVHP can target cells with VCAM-1 overexpression.

We further evaluated the targeting capability of UVHP to VCAM-1 with ICP-OES. The above MRI and statistical results have shown that UVHP can indeed target cells that are highly expressing VCAM-1. Cells (MAECs or HFLS-RA cells) were treated with TNF- $\alpha$ for $24 \mathrm{~h}$ and then incubated with different concentrations of UVHP (Fe concentration 25, 50, 100, $200 \mu \mathrm{g} /$ $\mathrm{mL}$ ). We found that the iron content in both cells was limitedly increased with the increase in UVHP concentration (Figure 4D and Figure $\mathbf{4 H}$ ). At the same time, compared with the TNF- $\alpha$ treatment groups, the uptake of Fe was also significantly increased 


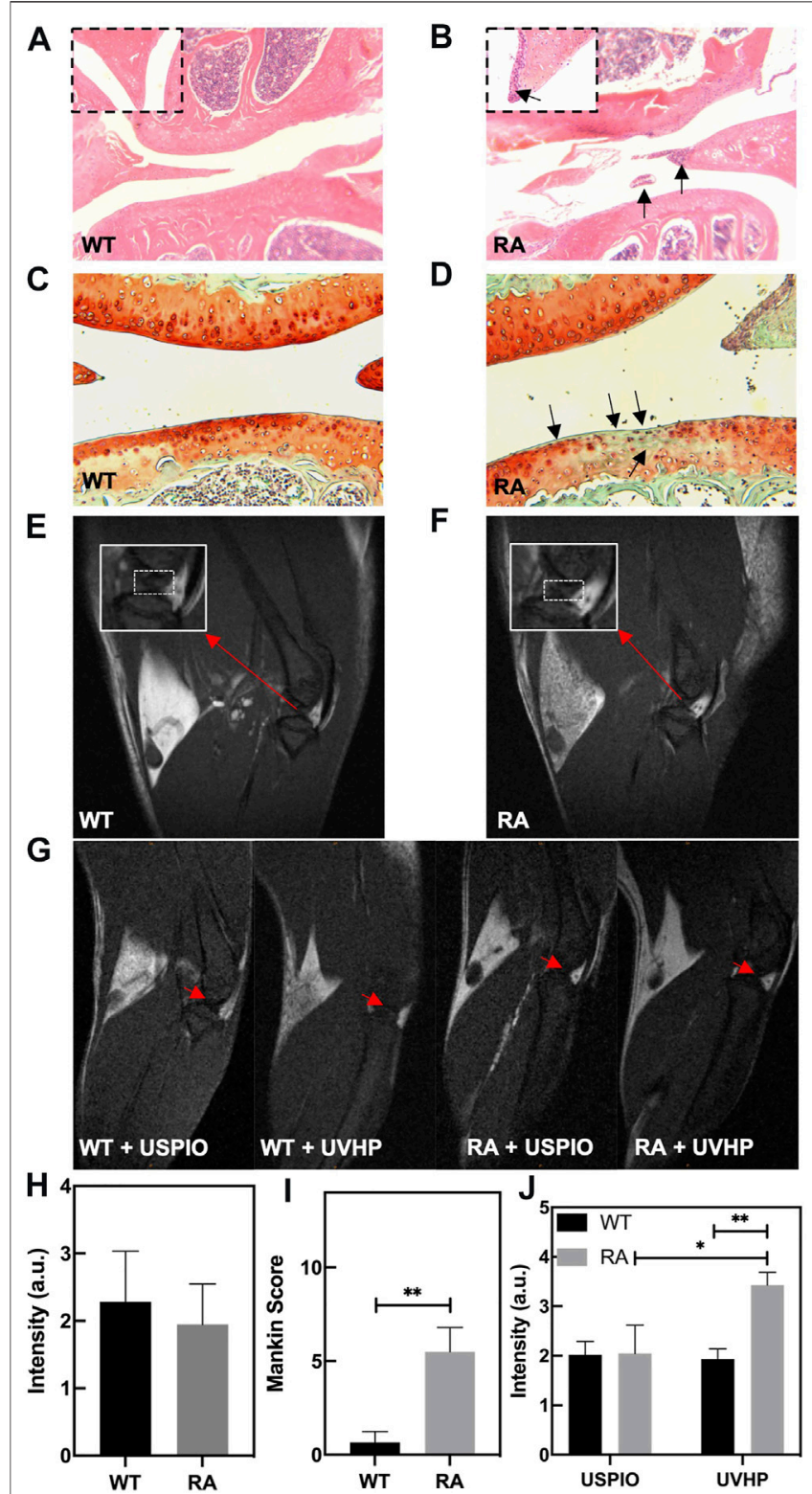

FIGURE 5 | Photomicrographs of representative hematoxylin and eosin (H\&E)-stained sections of knee joint from WT mice (A) and RA mice (B). The arrow shows the infiltration of inflammatory cells. (C,D) Safranin O/fast green staining sections of knee joint from WT mice (C) and RA mice (D). The arrow shows the cartilage layer lesion area. (E,F) $T_{1}$-weighted MRI of the knee joint in WT and RA mice; red arrows indicate the site of interest. (G) $T_{1}$ weighted MRI of the knee joint in WT and RA mice injected with UVHP through the tail vein, at the same time WT and RA mice injected with USPIO in the tail vein as controls; red arrows indicate the site of interest. (H) MRI signal value of $\mathrm{T}_{1}$-weighted MRI of the knee joint in WT and RA mice. (I) Mankin score of knee joints in WT and RA mice. (J) Signal value of T1-weighted MRI of the knee joint in WT and RA mice injected with USPIO and UVHP, respectively.

under PBS treatment with increasing UVHP concentration, but overall significantly lower than in the TNF- $\alpha$ treatment group with the same UVHP concentration (Figure 4D and Figure 4H). These results further confirmed that UVHP had a targeted function at the cellular level.

\subsection{RA Model Mice Construction and UVHP Targeting Joint MRI}

RA model mice construction details are listed in Materials and Methods. The knee joint sections of the model mice were taken for $\mathrm{H} \& \mathrm{E}$ staining and safranin $\mathrm{O} /$ fast green staining.

Compared with normal mice (Figure 5A), there are inflammatory cells immersed in the knee joint and the synovium observed in the RA model mice (Figure 5B). The safranin O/fast green staining showed that the cartilage structure of the RA model mice (Figure 5D) was destroyed. The cartilage surface was rough, and the cartilage cells were decolorized. The Mankin score (Figure 5I) of the RA model mice was significantly higher than that of WT mice, and it was in the early stage (Ehrlich et al., 1978). These results indicate that we established the RA model mice successfully.

To confirm the targeting joint MRI effect of UVHP on RA mice, first, we performed $\mathrm{T}_{1}$-weighted MRI on normal WT and RA mice, respectively. As shown in Figures $5 \mathbf{E}, \mathbf{F}$, the area framed by the dashed line is the synovial fluid region between the joints. Our statistics for this part of the area showed that there was no significant difference between normal WT and RA mice (Figure 5H).

Next, we injected USPIO and UVHP to normal WT mice and RA mice via the tail vein, respectively; $24 \mathrm{~h}$ later, we performed a $\mathrm{T}_{1^{-}}$ weighted MRI of the joint area (Figure 5G). The signal values of the synovial region between the joints were counted, and the results are shown in Figure 5J. There was no significant difference in signal values between WT and RA mice after USPIO injection, but the signal values of RA mice were significantly higher than those of WT mice after UVHP injection (Figure 5J). This indicates that more UVHPs were enriched at the joint region of RA mice, whereas USPIO was not enriched at that region. These results proved that UVHP could be targeted to joints of RA mice. To further confirm that UVHP could target the RA region, the changes of Fe content in the knee joint were tested by ICP-OES. The results show that there was no significant difference in Fe content in the knee joints of the WT and RA mice injected with USPIO, but the RA mice injected with UVHP showed a significant increase in Fe content in the knee joints of RA mice (Figure 6A), which was consistent with our MRI results (Figure 5J). This indicates that UVHP could target the joints of the RA model mice.

\subsection{Biodistribution of UVHP in vivo}

After injection of USPIO and UVHP via the tail vein to the RA mice $24 \mathrm{~h}$ later, these mice were euthanized. The Fe content of the heart, liver, spleen, lung, and kidney was quantified by ICP-OES. The results show that comparing with the order of the $\mathrm{Fe}$ distribution in RA mice: the spleen, heart, lung, liver, and kidney (from high to low) (Figure 6B), after injection of USPIO or UVHP to RA mice, the order of the Fe distribution in RA mice was spleen, liver, heart, lung, and kidney. The Fe contents in the spleen and liver of RA mice injected with USPOI or UVHP were significantly higher than those injected with PBS, indicating that most of the USPIO and UVHP were absorbed in the spleen and liver. Reports show more phagocytosis of nanoparticles by macrophages in the liver and spleen (Maldiney et al., 2014), suggesting that RA mice may mainly metabolize UVHP through the liver and spleen. 
A

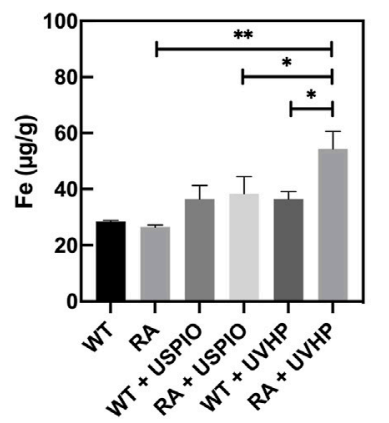

C

RA

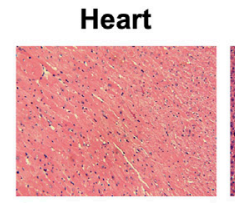

RA + UVHP
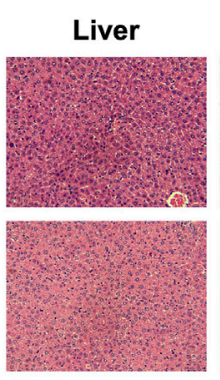

B

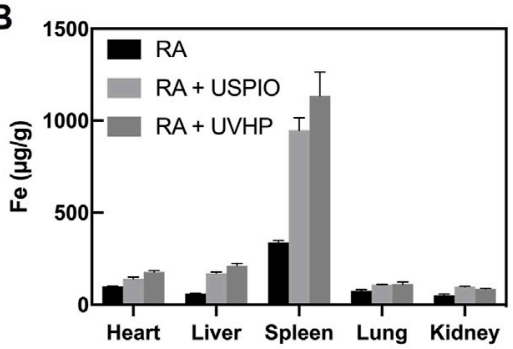

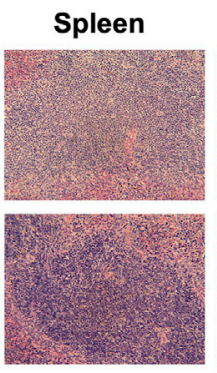
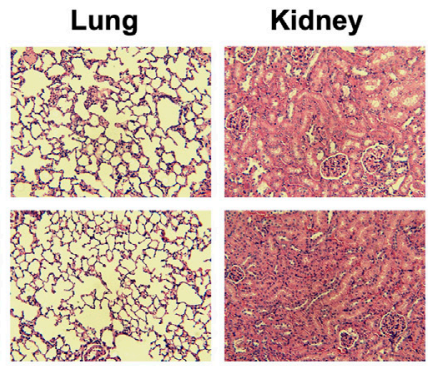

FIGURE 6 | Fe content in different tissues. (A) Elemental Fe content in the knee joint $24 \mathrm{~h}$ after tail vein injection of USPIO, UVHP to RA mice, WT mice, and PBSinjected RA mice, with WT mice as control. Each group ( $n=3$ per group) was injected with an equal Fe concentration (250 $\mu \mathrm{g}$ Fe, in $0.1 \mathrm{~mL}$ PBS). (B) Biodistribution of Fe in the major organs (heart, liver, spleen, lung, kidney) in RA mice $(n=3)$ at 24 h after intravenous administration of the USPIO, UVHP (250 $\mu g$ Fe, in $0.1 \mathrm{~mL}$ PBS). The Fe content of each organ was measured by ICP-OES. RA mice $(n=3)$ injected with PBS served as controls. (C) Sections of each organ (heart, liver, spleen, lung, kidney). The tail vein of RA mice ( $n=3$ ) was injected with UVHP (Fe contains $250 \mu \mathrm{g}$ in $0.1 \mathrm{~mL}$ PBS), and H\&E staining of each organ (heart, liver, spleen, lung, kidney) was performed after 14 days. RA mice $(n=3)$ injected with saline served as control.

\subsection{Safety Evaluation of UVHP}

Section pictures of organs stained by H\&E were used to investigate the biosafety of UVHP. The morphological analysis (Figure 6C) showed that compared with RA mice injected with PBS, the morphology of major organs (the heart, lung, liver, spleen, and kidney) still showed no significant change after injecting UVHP to RA mice for 14 days, which indicates UVHP had no significant influence on RA mice.

\section{DISCUSSION}

Magnetic iron oxide nanoparticles $(>50 \mathrm{~nm})$ are commonly used as $\mathrm{T}_{2}$ contrast agents; but when their size is reduced to small diameters (usually $<5 \mathrm{~nm}$ ), the particle surface area increases dramatically, causing relaxation changes of iron nearby water protons (Zhou et al., 2015). Although a large number of studies have explored the potential of USPIO as a $\mathrm{T}_{1}$ contrast agent, Shen et al. synthesized a series of USPIO (sizes from 1.9 to $4.9 \mathrm{~nm}$ ) to explore the optimal size for making $\mathrm{T}_{1}$-weighted MRI contrast agents, and the results show that $3.6 \mathrm{~nm}$ was the optimal size (Shen et al., 2017). Multiple factors affect $\mathrm{T}_{1}$-weighted MRI of USPIO, including size, shape, composition, surface coating, hydrophobicity, and degree of aggregation of USPIO (Jeon et al., 2021). The average size of our synthesized USPIO was $4.7 \mathrm{~nm}$, and the UVHP potential was $-27.7 \mathrm{mV}$ with good dispersion, and our results confirm that UVHP targeted not only the cells with high VCAM-1 expression but also the RA mice joint sites, which indicates the potential of
UVHP as a $\mathrm{T}_{1}$ contrast agent. In the process of USPIO and UVHP being engulfed by cells or entering living tissues, USPIO and UVHP aggregation may occur and lead to enhancement of $\mathrm{T}_{2}$-weighted MRI (Roch et al., 2005); thus, we speculate that our synthesized USPIO and UVHP may be suitable for both $\mathrm{T}_{1^{-}}$and $\mathrm{T}_{2}$-weighted MRI.

Because of the central role of macrophages in the pathogenesis of RA (Mulherin et al., 1996; Kinne et al., 2007), current contrast agents targeting RA imaging are focused on macrophages. Folic acid (Dai et al., 2014) or other molecules were utilized to target inflammatory macrophages in RA area (Hou et al., 2020). Based on the mechanism of inflammatory factors in the synovial fluid of RA patients leading to high VCAM-1 expression in synovial tissue (Carter and Wicks, 2001), we used UVHP targeting VCAM-1 of MAECs in RA. ICP-OES test results proved that UVHPs were enriched in arthritis and may provide a new targeting RA contrast agent for medical MRI.

Most $\mathrm{T}_{1}$-weighted contrast agents targeting $\mathrm{RA}$ are based on $\mathrm{Gd}$ reagents. For example, Hou. et al. synthesized the RA contrast agent CB86-DTPA-Gd targeting translocator protein based on Ga chelates (Hou et al., 2020). The risk of Gd long-term toxicity may trigger nephrogenic systemic fibrosis, as well as Gd deposition in the brain (Todd et al., 2007; Wei et al., 2017). Many studies have demonstrated the biosafety of USPIO, including at the cellular level, such as in hepatocytes (He et al., 2018) and stem cells (Ledda et al., 2020), and at the biological level, such as in mice (Ledda et al., 2020) and rats (Garcia-Fernandez et al., 2020). Through CCK-8 assays, hemolysis assays, and organ $\mathrm{H} \& \mathrm{E}$ staining section assays, we demonstrated that UVHP has good biosafety at the cell and tissue levels. 
In vitro experiments with cultured human monocytes have shown that various iron oxides have different abilities to be phagocytosed, with SPIO being more readily taken up by human monocytes than USPIO (Metz et al., 2004). In vivo, the larger particles (SPIO) are mainly taken up by macrophage cells in the liver, whereas the smaller particles (USPIO) are mainly taken up by macrophages in the bone marrow, lymph nodes, and spleen (Weissleder et al., 1990). Our results show that ultimately only a smaller amount of UVHP is concentrated in the RA lesion area. Analysis on the distribution of UVHP in the organism should also note that UVHP was less concentrated in the RA lesion region in contrast to the liver, spleen, heart, lung, and kidney. Based on the above results, we speculate that USPIO and UVHP may have the function of $\mathrm{T}_{1}$-weighted MRI similar to Gd. We look forward to further in-depth research later.

\section{CONCLUSION}

In summary, we synthesized a simple, low-cost, and less toxic contrast agent UVHP, which targets VCAM-1 and may be useful for earlystage RA diagnosis and generate high contrast in $\mathrm{T}_{1}$-weighted MRI.

\section{DATA AVAILABILITY STATEMENT}

The original contributions presented in the study are included in the article/Supplementary Material, further inquiries can be directed to the corresponding authors.

\section{REFERENCES}

Abdel-Nasser, A. M., Rasker, J. J., and Vaikenburg, H. A. (1997). Epidemiological and Clinical Aspects Relating to the Variability of Rheumatoid Arthritis. Semin. Arthritis Rheum. 27, 123-140. doi:10.1016/S0049-0172(97)80012-1

Caravan, P. (2006). Strategies for Increasing the Sensitivity of Gadolinium Based MRI Contrast Agents. Chem. Soc. Rev. 35, 512-523. doi:10.1039/B510982P

Carr, D., Brown, J., Bydder, G., Steiner, R., Weinmann, H., Speck, U., et al. (1984). Gadolinium-DTPA as a Contrast Agent in MRI: Initial Clinical Experience in 20 Patients. Am. J. Roentgenol. 143, 215-224. doi:10.2214/ajr.143.2.215

Carter, R. A., and Wicks, I. P. (2001). Vascular Cell Adhesion Molecule 1 (CD106): a Multifaceted Regulator of Joint Inflammation. Arthritis Rheum. 44, 9852-9994. doi:10.1002/1529-0131(200105)44:5<985:aid-anr176>3.0.co;2-p

Chen, S., Zhang, Q., Sun, H., Zheng, Y., Chen, Q., Luo, Y., et al. (2020). A Cation Exchange Strategy to Construct a Targeting Nanoprobe for Enhanced T1-Weighted MR Imaging of Tumors. J. Mater. Chem. B 8, 8519-8526. doi:10.1039/d0tb01632b

Choy, E. H. S., and Panayi, G. S. (2001). Cytokine Pathways and Joint Inflammation in Rheumatoid Arthritis. N. Engl. J. Med. 344, 907-916. doi:10.1056/NEJM200103223441207

Croft, D., McIntyre, P., Wibulswas, A., and Kramer, I. (1999). Sustained Elevated Levels of VCAM-1 in Cultured Fibroblast-like Synoviocytes Can Be Achieved by TNF- $\alpha$ in Combination with Either IL-4 or IL-13 through Increased mRNA Stability. Am. J. Pathol. 154 (4), 1149-1158. doi:10.1016/S0002-9440(10)65367-9

Dai, F., Du, M., Liu, Y., Liu, G., Liu, Q., and Zhang, X. (2014). Folic AcidConjugated Glucose and Dextran Coated Iron Oxide Nanoparticles as MRI Contrast Agents for Diagnosis and Treatment Response of Rheumatoid Arthritis. J. Mater Chem. B 2 (16), 2240-2247. doi:10.1039/c3tb21732a

da Costa Moura, C. (2013). Development of Multifunctional Nanoparticles for Targeted Therapy and Imaging of Rheumatoid Arthritis: Faculty of Engineering University of Porto.

\section{ETHICS STATEMENT}

The animal study was reviewed and approved by the Institutional Animal Ethics Committee of South China Normal University.

\section{AUTHOR CONTRIBUTIONS}

$\mathrm{CuZ}, \mathrm{YL}$, and WH: conceptualization and compilation of data. $\mathrm{CuZ}$ and WC: writing part and proofreading. $\mathrm{CuZ}, \mathrm{QZ}$, and $\mathrm{CH}$ : designing of figure. CuZ, CeZ, YT, WW, YL, and YT: language polishing. All authors contributed to the article and approved the submitted version.

\section{FUNDING}

This work was supported by the National Natural Science Foundation of China (No. 81471659), Guangzhou Science and Technology Planning Project (202103000002), Guangdong Medical Science and Technology Research Foundation (B2021376) and Panyu Major Science and Technology Planning Project (2020-Z04-002).

\section{SUPPLEMENTARY MATERIAL}

The Supplementary Material for this article can be found online at: https://www.frontiersin.org/articles/10.3389/fbioe.2022.821256/ full\#supplementary-material

Dolati, S., Sadreddini, S., Rostamzadeh, D., Ahmadi, M., Jadidi-Niaragh, F., and Yousefi, M. (2016). Utilization of Nanoparticle Technology in Rheumatoid Arthritis Treatment. Biomed. Pharmacother. 80, 30-41. doi:10.1016/j.biopha.2016.03.004

Ehrlich, M. G., Houle, P. A., Vigliani, G., and Mankin, H. J. (1978). Correlation between Articular Cartilage Collagenase Activity and Osteoarthritis. Arthritis Rheum. 21 (7), 761-766. doi:10.1002/art.1780210704

Elices, M.-D. J. W. E., Mj, A.-G. J., Zvaifler, N., et al. (1992). a4ßl Integrin (VLAA) Ligands in Arthritis: Vascular Cell Adhesion Molecule Expression in Synovium and on Fibroblast-like Synoviocytes. J. Immunol. 149, 1424. PMID: 1380043.

Fan, X., Chen, X., Feng, Q., Peng, K., Wu, Q., Passerini, A. G., et al. (2019). Downregulation of GATA6 in mTOR-Inhibited Human Aortic Endothelial Cells: Effects on TNF- $\alpha$-Induced VCAM-1 Expression and Monocytic Cell Adhesion. Am. J. Physiol.-Heart Circ. Physiol. 316, H408-H420. doi:10.1152/ajpheart.00411.2018

Firestein, G. S. (2003). Evolving Concepts of Rheumatoid Arthritis. Nature 423, 356-361. doi:10.1038/nature01661

Garcia-Fernandez, J., Turiel, D., Bettmer, J., Jakubowski, N., Panne, U., Rivas García, L., et al. (2020). In Vitro and In Situ Experiments to Evaluate the Biodistribution and Cellular Toxicity of Ultrasmall Iron Oxide Nanoparticles Potentially Used as Oral Iron Supplements. Nanotoxicology 14, 388-403. doi:10. 1080/17435390.2019.1710613

He, C., Jiang, S., Yao, H., Zhang, L., Yang, C., Zhan, D., et al. (2018). Endoplasmic Reticulum Stress Mediates Inflammatory Response Triggered by Ultra-small Superparamagnetic Iron Oxide Nanoparticles in Hepatocytes. Nanotoxicology 12, 1198-1214. doi:10.1080/17435390.2018.1530388

Hou, Z., Wang, Q., Guo, Z., Wang, T., Wu, H., Ma, C., et al. (2020). Gadoliniumconjugated CB86: a Novel TSPO-Targeting MRI Contrast Agent for Imaging of Rheumatoid Arthritis. J. Drug Target. 28, 398-407. doi:10.1080/1061186X.2019. 1669040

Hu, Y., Li, J., Yang, J., Wei, P., Luo, Y., Ding, L., et al. (2015). Facile Synthesis of RGD Peptide-Modified Iron Oxide Nanoparticles with Ultrahigh Relaxivity for Targeted MR Imaging of Tumors. Biomater. Sci. 3, 721-732. doi:10.1039/C5BM00037H 
Iannitti, T., Elhensheri, M., Bingöl, A. Ö., and Palmieri, B. (2013). Preliminary Histopathological Study of Intra-articular Injection of a Novel Highly CrossLinked Hyaluronic Acid in a Rabbit Model of Knee Osteoarthritis. J. Mol. Hist. 44 (2), 191-201. doi:10.1007/s10735-012-9457-4

Jeon, M., Halbert, M. V., Stephen, Z. R., and Zhang, M. (2021). Iron Oxide Nanoparticles as $\mathrm{T} 1$ Contrast Agents for Magnetic Resonance Imaging: Fundamentals, Challenges, Applications, and Prospectives. Adv. Mater. 33, 1906539. doi:10.1002/adma. 201906539

Jones, G. W., Hill, D. G., Sime, K., and Williams, A. S. (2018). In Vivo Models for Inflammatory Arthritis. Methods Mol. Biol. 1725, 101-118. doi:10.1007/978-14939-7568-6_9

Jynge, P., Skjold, A. M., Falkmer, U., Andersson, R. G. G., Seland, J. G., Bruvold, M., et al. (2020). MnDPDP: Contrast Agent for Imaging and Protection of Viable Tissue. Contrast Media Mol. Imaging 2020, 1-17. doi:10.1155/2020/3262835

Kinne, R. W., Stuhlmüller, B., and Burmester, G.-R. (2007). Cells of the Synovium in Rheumatoid Arthritis. Macrophages. Arthritis Res. Ther. 9, 224-240. doi:10.1186/ ar2333

Kvien, T. K. (2004). Epidemiology and burden of Illness of Rheumatoid Arthritis. Pharmacoeconomic 22, 1-12. doi:10.2165/00019053-200422001-00002

Ledda, M., Fioretti, D., Lolli, M. G., Papi, M., Di Gioia, C., Carletti, R., et al. (2020). Biocompatibility Assessment of Sub-5 Nm Silica-Coated Superparamagnetic Iron Oxide Nanoparticles in Human Stem Cells and in Mice for Potential Application in Nanomedicine. Nanoscale 12 (3), 1759-1778. doi:10.1039/C9NR09683C

Li, X., Lu, S., Xiong, Z., Hu, Y., Ma, D., Lou, W., et al. (2019). Light-Addressable Nanoclusters of Ultrasmall Iron Oxide Nanoparticles for Enhanced and Dynamic Magnetic Resonance Imaging of Arthritis. Adv. Sci. 6, 1901800. doi:10.1002/advs. 201901800

Li, H., Han, J., and Liang, G. (2020). Phase Transfer of Hydrophobic Nanoparticles Using a Zwitterionic Sulfobetaine Siloxane Generates Highly Biocompatible and Compact Surfaces. ACS Appl. Nano Mater. 3, 1489-1496. doi:10.1021/acsanm.9b02306

Liu, H., Xu, Y., Wen, S., Zhu, J., Zheng, L., Shen, M., et al. (2013). Facile Hydrothermal Synthesis of Low Generation Dendrimer-Stabilized Gold Nanoparticles for In Vivo Computed Tomography Imaging Applications. Polym. Chem. 4, 1788. doi:10.1039/c2py20993d

Luo, Y., Yang, J., Yan, Y., Li, J., Shen, M., Zhang, G., et al. (2015). RGD-functionalized Ultrasmall Iron Oxide Nanoparticles for Targeted T1-Weighted MR Imaging of Gliomas. Nanoscale 7, 14538-14546. doi:10.1039/c5nr04003e

Luo, Q., Zhang, L., Li, X., Fu, B., Deng, Z., Qing, C., et al. (2018). Identification of Circular RNAs Hsa_circ_0044235 in Peripheral Blood as Novel Biomarkers for Rheumatoid Arthritis. Clin. Exp. Immunol. 194, 118-124. doi:10.1111/cei.13181

Maldiney, T., Bessière, A., Seguin, J., Teston, E., Sharma, S. K., Viana, B., et al. (2014). The In Vivo Activation of Persistent Nanophosphors for Optical Imaging of Vascularization, Tumours and Grafted Cells. Nat. Mater 13, 418-426. doi:10. 1038/nmat3908

Metz, S., Bonaterra, G., Rudelius, M., Settles, M., Rummeny, E., and Daldrup-Link, H. (2004). Capacity of Human Monocytes to Phagocytose Approved Iron Oxide MR Contrast Agents In Vitro. Eur. Radiol. 14, 1851-1858. doi:10.1007/s00330-004-2405-2

Meyer, D., Schaefer, M., and Bonnemain, B. (1988). Gd-DOTA, A Potential MRI Contrast Agent Current Status of Physicochemical Knowledge. Invest. Radiol. 23 (Suppl. 1), S232-S235. doi:10.1097/00004424-198809001-00048

Mulherin, D., Fitzgerald, O., and Bresnihan, B. (1996). Synovial Tissue Macrophage Populations and Articular Damage in Rheumatoid Arthritis. Arthritis Rheum. 39, 115-124. doi:10.1002/art.1780390116

Na, H. B., Song, I. C., and Hyeon, T. (2009). Inorganic Nanoparticles for MRI Contrast Agents. Adv. Mater. 21, 2133-2148. doi:10.1002/adma.200802366

Nahrendorf, M., Jaffer, F. A., Kelly, K. A., Sosnovik, D. E., Aikawa, E., Libby, P., et al. (2006). Noninvasive Vascular Cell Adhesion Molecule-1 Imaging Identifies Inflammatory Activation of Cells in Atherosclerosis. Circulation 114, 1504-1511. doi:10.1161/CIRCULATIONAHA.106.646380

Nishitani, K., Kobayashi, M., Kuroki, H., Mori, K., Shirai, T., Satake, T., et al. (2014). Ultrasound Can Detect Macroscopically Undetectable Changes in Osteoarthritis Reflecting the Superficial Histological and Biochemical Degeneration: Ex Vivo Study of Rabbit and Human Cartilage. PLOS ONE 9 (2), e89484. doi:10.1371/journal.pone.0089484

Østergaard, M., Pedersen, S. J., and Døhn, U. M. (2008). Imaging in Rheumatoid Arthritis - Status and Recent Advances for Magnetic Resonance Imaging, Ultrasonography, Computed Tomography and Conventional Radiography. Best Pract. Res. Clin. Rheumatol. 22, 1019-1044. doi:10.1016/j.berh.2008.09.014
Prince, M. R., Zhang, H., Morris, M., MacGregor, J. L., Grossman, M. E., Silberzweig, J., et al. (2008). Incidence of Nephrogenic Systemic Fibrosis at Two Large Medical Centers. Radiology 248, 807-816. doi:10.1148/radiol.2483071863

Roch, A., Gossuin, Y., Muller, R. N., and Gillis, P. (2005). Superparamagnetic Colloid Suspensions: Water Magnetic Relaxation and Clustering. J. Magnetism Magn. Mater. 293, 532-539. doi:10.1016/j.jmmm.2005.01.070

Shen, Z., Chen, T., Ma, X., Ren, W., Zhou, Z., Zhu, G., et al. (2017). Multifunctional Theranostic Nanoparticles Based on Exceedingly Small Magnetic Iron Oxide Nanoparticles for $\mathrm{T}_{1}$-Weighted Magnetic Resonance Imaging and Chemotherapy. ACS Nano 11, 10992-11004. doi:10.1021/acsnano.7b04924

Simon, G. H., von Vopelius-Feldt, J., Wendland, M. F., Fu, Y., Piontek, G., Schlegel, J., et al. (2006). MRI of Arthritis: Comparison of Ultrasmall Superparamagnetic Iron Oxide vs. Gd-DTPA. J. Magn. Reson. Imaging 23, 720-727. doi:10.1002/jmri.20556

Tao, C., Zheng, Q., An, L., He, M., Lin, J., Tian, Q., et al. (2019). T1-Weight Magnetic Resonance Imaging Performances of Iron Oxide Nanoparticles Modified with a Natural Protein Macromolecule and an Artificial Macromolecule. Nanomaterials 9, 170. doi:10.3390/nano9020170

Todd, D. J., Kagan, A., Chibnik, L. B., and Kay, J. (2007). Cutaneous Changes of Nephrogenic Systemic Fibrosis: Predictor of Early Mortality and Association with Gadolinium Exposure. Arthritis Rheum. 56, 3433-3441. doi:10.1002/art.22925

Tromsdorf, U. I., Bruns, O. T., Salmen, S. C., Beisiegel, U., and Weller, H. (2009). A Highly Effective, Nontoxic T1 MR Contrast Agent Based on Ultrasmall PEGylated Iron Oxide Nanoparticles. Nano Lett. 9, 4434-4440. doi:10.1021/nl902715v

Wei, H., Bruns, O. T., Kaul, M. G., Hansen, E. C., Barch, M., Wiśniowska, A., et al. (2017). Exceedingly Small Iron Oxide Nanoparticles as Positive MRI Contrast Agents. Proc. Natl. Acad. Sci. USA 114, 2325-2330. doi:10.1073/pnas.1620145114

Weissleder, R., Elizondo, G., Wittenberg, J., Rabito, C. A., Bengele, H. H., and Josephson, L. (1990). Ultrasmall Superparamagnetic Iron Oxide: Characterization of a New Class of Contrast Agents for MR Imaging. Radiology 175, 489-493. doi:10.1148/radiology.175.2.2326474

Xu, W., Zhang, S., Zhou, Q., and Chen, W. (2019). VHPKQHR Peptide Modified Magnetic Mesoporous Nanoparticles for MRI Detection of Atherosclerosis Lesions. Artif. Cell Nanomed. Biotechnol. 47, 2440-2448. doi:10.1080/21691401.2019.1626411

Yang, Y., Zhang, T., and Xing, D. (2021). Single $808 \mathrm{Nm}$ Near-Infrared-Triggered Multifunctional Upconverting Phototheranostic Nanocomposite for Imaging-Guided High-Efficiency Treatment of Tumors. J. Biophotonics 14, e202100134. doi:10.1002/ jbio.202100134

Yu, Z., Peng, C., Luo, Y., Zhu, J., Chen, C., Shen, M., et al. (2015). Poly ( $\gamma$-glutamic Acid)Stabilized Iron Oxide Nanoparticles: Synthesis, Characterization and Applications for MR Imaging of Tumors. RSC Adv. 5, 76700-76707. doi:10.1039/c5ra15814a

Zhao, J., Chen, X., Ho, K.-H., Cai, C., Li, C.-W., Yang, M., et al. (2021). Nanotechnology for Diagnosis and Therapy of Rheumatoid Arthritis: Evolution towards Theranostic Approaches. Chin. Chem. Lett. 32, 66-86. doi:10.1016/j.cclet.2020.11.048

Zhou, Z., Wu, C., Liu, H., Zhu, X., Zhao, Z., Wang, L., et al. (2015). Surface and Interfacial Engineering of Iron Oxide Nanoplates for Highly Efficient Magnetic Resonance Angiography. ACS Nano 9, 3012-3022. doi:10.1021/nn507193f

Zhou, H., Qiu, X., and Shen, Z. (2020). $\mathrm{T}_{1}$-weighted Magnetic Resonance Imaging Contrast Agents and Their Theranostic Nanoprobes. Nan fang Yi ke da Xue Xue Bao = J. South. Med. Univ. 40, 427-444. doi:10.12122/j.issn.1673-4254.2020.03.24

Conflict of Interest: The authors declare that the research was conducted in the absence of any commercial or financial relationships that could be construed as a potential conflict of interest.

Publisher's Note: All claims expressed in this article are solely those of the authors and do not necessarily represent those of their affiliated organizations, or those of the publisher, the editors and the reviewers. Any product that may be evaluated in this article, or claim that may be made by its manufacturer, is not guaranteed or endorsed by the publisher.

Copyright $\odot 2022$ Zhang, Huang, Huang, Zhou, Tang, Wei, Li, Tang, Luo, Zhou and Chen. This is an open-access article distributed under the terms of the Creative Commons Attribution License (CC BY). The use, distribution or reproduction in other forums is permitted, provided the original author $(s)$ and the copyright owner $(s)$ are credited and that the original publication in this journal is cited, in accordance with accepted academic practice. No use, distribution or reproduction is permitted which does not comply with these terms. 